\title{
Drugs Implicated In Seizures and Its Management
}

\author{
Pooja H Vaidya ${ }^{1 *}$ and Anup U Petare ${ }^{2}$ \\ ${ }^{1}$ Specialty Medical Officer, India \\ ${ }^{2}$ Assistant Manager, Medical Services, India
}

Submission: June 14, 2017; Published: July 03, 2017

*Corresponding author: Pooja H Vaidya, Pharmacology,Speciality Medical Officer LTMMC \& GH, Sion, Mumbai, Address: L-12/D-wing/504, Vighnaharta CHS, Pratiksha Nagar, Sion, Mumbai-22, India, Tel: 9664359836; Email: poojahvaidya@gmail.com

\begin{abstract}
Drug-induced seizures are a potentially serious adverse effect. This article provides a comprehensive review of drugs that are most commonly associated with seizures as an adverse drug reaction. The epidemiology, pathophysiology, various predisposing factors, and the drug classes implicated in seizures have been extensively reviewed to provide the physicians with treatment alternatives, especially, in high risk cases. Moreover, the review delineates the management of patients with drug induced seizures briefly. We hope to assist the clinicians by revising data regarding drugs class and individual medications associated with seizures and its management.
\end{abstract}

Keywords: Convulsion; Adverse drug reaction; Drug withdrawal; Generalized tonic-clonic seizures

\section{Introduction}

Seizures in a patient taking a medically prescribed drug are a serious adverse drug reaction $[1,2]$. Drug induced seizures occur either due to exposure to or withdrawal from a medication, drug or a toxin [3]. The vital drug factors responsible for a seizure include class of drug, dose and route of administration. Whereas, the patient factors that predispose to drug induce seizures include pre-existing neurological illness, concomitant medical illnesses, old age, liver failure, renal insufficiency, family history of epilepsy, non-compliance with anti-epileptic treatment, use of concomitant drugs, stress, sleep deprivation, and alcohol abuse [2]. These factors together lower the seizure threshold. Majority of these seizures are self-limited and do not cause permanent sequelae. Nonetheless, repeated or prolonged seizure activity can cause irreversible neurological injury and life-threatening complications including hypoxia, hypotension, pulmonary aspiration, hyperthermia, rhabdomyolysis and metabolic acidosis [3]. Data about drugs commonly responsible for druginduced seizures is limited, particularly in children. Moreover, thorough acquaintance with the likely causative agents would be valuable to clinicians and could potentially guide the therapeutic approach.

\section{Review}

\section{Epidemiology}

According to the published literature, $6 \%$ of new-onset generalized tonic colonic seizures in individuals older than 16 years presenting to the emergency department at a single center over a five year period were ascribed to drug exposures, excluding alcohol withdrawal which accounted for $17.6 \%$ cases [4]. In another study in an urban hospital, $9 \%$ of adults treated for status epilepticus had drug induced seizures [5]. The drugs causing seizures does vary geographically. Two studies in USA showed that antidepressants were the most common drug class implicated, with bupropion being the most commonly identified drug followed by anticholinergics $[6,7]$. In Switzerland, mefenamic acid and citalopram were the most commonly implicated drugs in seizures [8]. In Iran and Australia, tramadol overdose was the common cause of seizures and herbicides and insecticides were implicated in developing countries [3]. A study in the USA recognized that the drugs responsible for seizures showed rapid transition from cocaine, benzodiazepine withdrawal, and tricyclic antidepressants to atypical antidepressants [6].

\section{Pathophysiology}

Typically, seizure activity results when there is a sudden onset of disparity between the excitatory and the inhibitory forces in the cerebral cortex resulting in uncontrolled neuronal stimulation. The primary neurotransmitters involved are acetylcholine, gammaaminobutyric acid (GABA), and glutamate. Periodic oscillations of these neuro-transmitters occur in the thalamiccortical circuit and are regulated by serotonergic, noradrenergic and cholinergic brainstem pathways [9]. Drugs can decrease the inhibitory GABA neurotransmission and lead to over activation resulting in seizures due to membrane depolarization 
[3]. For e.g. isoniazid or cephalosporin overdose causes seizures by decrease in GABAergic neurotransmission [10]. The release of excitatory neurotransmitter glutamate is mediated by three main receptors: NMDA, AMPA/kainite, and metabotropic. Chronic ethanol use leads to an increase in NMDA receptors. On sudden cessation of alcohol use, the increased neuroexcitatory tone is unmasked which may trigger convulsions [11].

However, no single mechanism can explain all cases of druginduced seizures [3]. Certain drugs cause secondary seizures through indirect effects on brain perfusion, oxygenation or metabolic disturbances. Narcotics induce hypoxaemia and seizures by direct injury to lung parenchyma or by pulmonary aspiration of gastric contents [9]. Carbon monoxide and cyanide interfere with cellular oxygen utilization resulting in hypoxia and seizures. Even electrolyte disturbances such as hyponatraemia, hypomagnesaemia and hypoglycaemia can lead to seizures. For e.g. sulfonylureas induce seizures via hypoglycaemia, 3, 4-Methylenedioxymethamphetamine (MDMA) via hyponatremia, salicylates via cerebral oedema $[1,2,6]$.

Some toxins such as strychnine can induce spinal seizures characterized by involuntary muscle contraction, myoclonus, hyper reflexia and opisthotonus without loss of consciousness. Strychnine competitively inhibits the action of glycine, a major inhibitory neurotransmitter in the spinal cord and brain stem and results in seizures. Similarly, tetanus toxin prevents the release of glycine from the pre-synaptic membrane and induces seizures [3].

\section{Drugs Frequently Implicated in Drug Induced Seizures}

Table 1: Drugs frequently implicated in causing seizures

\begin{tabular}{|c|c|}
\hline Class of drugs & Examples \\
\hline Anti-epileptics & $\begin{array}{c}\text { Phenytoin, carbamazepine, lamotrigine, tiagabine, } \\
\text { vigabatrin }\end{array}$ \\
\hline $\begin{array}{l}\text { Antidepressants } \\
\text { and } \\
\text { Antipsychotics }\end{array}$ & $\begin{array}{l}\text { Tricyclic antidepressants, citalopram, } \\
\text { escitalopram, bupropion, SSRI, venlafaxine, } \\
\text { lithium, chlorpromazine, phenothiazine, } \\
\text { clozapine, olanzapine, quetiapine }\end{array}$ \\
\hline Analgesics & $\begin{array}{l}\text { Propoxyphene, tramadol, mefenamic acid, } \\
\text { salicylates, meperidine, Phenylbutazone }\end{array}$ \\
\hline Drugs of Abuse & $\begin{array}{l}\text { Cocaine, amphetamines, MDMA, phencyclidine, } \\
\text { ketamine }\end{array}$ \\
\hline Withdrawal & Ethanol, baclofen, sedatives - hypnotics \\
\hline $\begin{array}{l}\text { Miscellaneous } \\
\text { agents }\end{array}$ & $\begin{array}{l}\text { Methylxanthines, isoniazid, anticholinergics, } \\
\text { organochlorine pesticides, organophosphate } \\
\text { pesticides, camphor, lindane, nerve agents, } \\
\text { carbamates, chloroquine, quinine, asphyxiants, } \\
\text { Iron }\end{array}$ \\
\hline $\begin{array}{c}\text { Natural } \\
\text { Substances }\end{array}$ & $\begin{array}{l}\text { Gyomitra esculenta (mushrooms), jimson weed } \\
\text { (Datura stramonium), ephedra }\end{array}$ \\
\hline
\end{tabular}

The important drug related characteristics that contribute to the condition include intrinsic epileptogenicity of the substance, dose, route, and central nervous system (CNS) levels. Drugs with a high lipid solubility, low molecular weight, and low protein binding and weakly polar are more likely to enter the CNS [2,9]. Drugs implicated in instigating seizures are broadly classified as psychotropic and non-psychotropic agents. Seizures may also occur as an indirect effect of antiepileptic drugs, miscellaneous agents and drug-drug interactions. Psychotropic drugs include antidepressants, antipsychotics and anti-epileptics, whereas non-psychotropic agents include narcotics, methylxantines, anticholinergics and several miscellaneous drugs as described herewith (Table 1) [1].

\section{Psychotropic agents inducing seizures}

a) Anti-epileptics: Occurrence of seizures after anticonvulsant overdose is a rare finding and can occur after exposure to phenytoin, carbamazepine, vigabatrin, tiagabine, and lamotrigine [12]. The elderly are at a higher risk of confusion and medication misuse, thus increasing the likelihood of seizures. Moreover, exacerbation of pre-existing seizures may ensue because of acute or chronic toxicity, sudden withdrawal or by an indirect mechanism. For e.g. Carbamazepine can lead to seizures via inappropriate antidiuretic hormone secretion and hyponatraemia [12].

b) Antidepressants and Antipsychotics: Incidence of seizures at therapeutic doses of antidepressants and antipsychotics range from $0.11 .5 \%$. In overdose, the risk increases to 4 to $30 \%$. Skowron et al. [13] has categorized the antidepressants in order of their probability to precipitate seizures (Table 2).

Table 2: Seizures induced by Antidepressant.

\begin{tabular}{|c|c|}
\hline $\begin{array}{l}\text { Probability of } \\
\text { inducing seizures }\end{array}$ & Antidepressants \\
\hline High & $\begin{array}{c}\text { Clomipramine, amoxapine, maprotiline, } \\
\text { bupropion }\end{array}$ \\
\hline Intermediate & $\begin{array}{l}\text { Amitryptiline, imipramine, desipramine, } \\
\text { nortryptiline, protryptiline, doxepin }\end{array}$ \\
\hline Low & $\begin{array}{l}\text { Fluoxetine, sertraline, paroxetine, fluvoxamine, } \\
\text { trazodone }\end{array}$ \\
\hline Minimal & Tranylcypromine, phenelzine \\
\hline
\end{tabular}

c) Tricyclic antidepressants (TCA): Most of TCA induced seizures are associated with acute overdose with an incidence of $10 \%$ with drug overdose. The mortality rate from overdose remains significantly more up to $10 \%$ than other antidepressants. A study of TCA induced seizures has shown that seizures are generalized, brief, and occur within 1.5 hours of ingestion. Sustained seizures may occur in up to $17 \%$ cases of TCA overdose. Of all the TCA's, clomipramine has been reported to have a greater seizure risk at doses greater than $300 \mathrm{mg} /$ day [14].

d) Bupropion: A monocyclic antidepressant was initially withdrawn from the U.S. market due to possibility of seizures, but was reintroduced later. Thundiyil et al [7] has demonstrated that bupropion is the most common cause of new onset seizures attributable to drug exposures. In studies of bupropion overdoses, the seizure incidence ranges 
from 11 15\% and this rate was highest among those taking an extended release preparation. A significant number of patients experienced seizures greater than 8 hours post ingestion [15].

e) Citalopram and Escitalopram: Seizures occur in 515\% of overdose cases. Citalopram induced QT prolongation; sedation, bradycardia, and hypotension indirectly cause convulsions [16].

f) Venlafaxine: Seizures are observed in $0.26 \%$ of patients at therapeutic doses, whereas in overdose, it has dose dependent proconvulsant effects with an incidence up to $14 \%$. Doses in the range of $9001500 \mathrm{mg}$ are associated with seizures.

g) Antipsychotics: First generation antipsychotics have a low incidence of seizures. A cohort study done retrospectively showed that second generation antipsychotics carry significant seizure risk. The seizure incidence appears to be highest with clozapine $(2.8 \%)$ and olanzapine (2\%). Clinical reports imply that haloperidol, molindone, pimozide, thioridazine, thiothixene and risperidone exhibit lowest seizurogenic effects. Factors implicated in the occurrence of seizures in patients receiving antipsychotics include elderly age group, high dose therapy and rapid titration. Moreover, risk of seizure is greater in epileptics as competitive enzyme inhibition by the anti-psychotics decrease anticonvulsant serum concentrations and can precipitate convulsions [1].

h) Specific stimulants: Cocaine, neither amphetamines, MDMA exhibit proconvulsant effect probably attributed to increase in nor epinephrine and serotonin levels. Stimulant induced seizures are associated with a higher mortality rate. A case series determined that 3 out of 7 deaths were attributed to stimulant abuse induced seizures [7]. Cocaine can trigger seizures in patients with epilepsy and alcoholic patients during the process of detoxification. Though less common, but a single dose of amphetamines or analogous substance (e.g., ephedra) can trigger seizures cluster. Amphetamines are the fifth leading cause of drug induced seizures due to their direct effects on serotonin and indirect effects of hyponatremia. Mortality due to MDMA is directly linked with number of seizures [17].

\section{Non-Psychotropic Agents Inducing Seizures}

i. Narcotics: An estimated incidence of seizures in opioid abusers in $12.5 \%$. Seizures occur in as many as $20.2 \%$ of patients presenting with propoxyphene abuse. Of these seizures, $87 \%$ were generalized tonic-clonic and typically manifest in 2 hours. The metabolite of meperidine, normeperidine, is highly epileptogenic. There exists an increased risk with high doses or in patients with compromised kidney function [18]. In case of Tramadol, seizures occur not only in overdoses but even in therapeutic dose. The convulsions are not dose dependent. A study revealed 13.7\% incidence of seizures in patients on tramadol and chronic use increased risk. Seizure activity also has been reported when reversing the effects of tramadol by using naloxone [19].

ii. dMethylxanthines: Seizures can occur even at therapeutic doses and are more likely to occur with serum levels of greater than $100 \mathrm{mg} / \mathrm{dL}$ in acute exposures and $60 \mathrm{mg} / \mathrm{dL}$ in chronic toxicity. Preclinical data suggest that blockade of the adenosine A1 receptor is the mechanism for theophylline induced seizures [20].

iii. Isoniazid: In case of overdoses, deficiency of pyridoxine which is required to convert glutamate to GABA is suggested as the causative factor for seizures. A retrospective review of 52 cases of INH overdoses reported that seizures were found in $100 \%$ cases. A natural substance commonly known as the false morel mushroom (Gyromitra esculenta) acts by similar mechanism. It is metabolized into monomethyl-hydrazine, which is structurally similar to isoniazid and results in functional depletion of pyridoxine and vitamin B6 [10].

iv. Anticholinergic Drugs: These are reported to account for up to $10 \%$ of drug implicated in seizures [7]. Diphenhydramine is the most commonly ingested anticholinergic agent and can cause seizures in overdose. Jimson weed (Datura stramonium) is a common weed consumed for its hallucinogenic and euphoric effects in the United States, and toxicity often results due to intentional ingestion by teenagers. It contain the belladonna alkaloids atropine, Lhyoscyamine, and L-scopolamine causing anticholinergic toxicity and seizures [7,9]. Household toxins like camphor and phenol can be ingested accidentally. Khine et al. [21] reported a cluster of seizures induced by camphor in children associated with illegally sold or imported camphor products.

v. Local Anaesthetics: Toxicity can be seen when excessive doses are administered eg. Lignocaine in doses exceeding $4.5 \mathrm{mg} / \mathrm{kg}$. Higher dose symptoms include CNS excitation, seizures followed by respiratory depression, coma [22].

\section{Drug withdrawal inducing seizures}

The common drugs triggering seizures due to sudden withdrawal include mainly alcohol and sedative-hypnotics. Drug withdrawal results in decrease in GABA and subsequent loss of NMDA receptor inhibition. The result is increased glutamate stimulation, excitatory and a hyperadenergic state with potential for seizure activity. In ethanol withdrawal, seizures occur typically within 648 hours after cessation of drinking. The onset of symptoms after benzodiazepine withdrawal is not as predictable due to varying half-lives and pharmacokinetics of the various agents $[1,7]$.

\section{Clinical Presentation of Drug Induced Seizures}

Differentiating drug and toxin induced seizures from other causes is a difficult task unless there is a history of overdose of any specific drug. In conditions wherein there is no history of 
epilepsy, patient is not hypoxic or hypoglycaemic, the physician should maintain a high index of suspicion to consider drugs or toxins as the aetiology. Conversely, in case of focal seizure, if there is no alteration in level of consciousness or a post ictal period, then the seizure is unlikely to be drug related. there is suspicion for drug induced seizures, the patient's past and family history, current illness and certain clinical clues can prove useful. The patient's access to medications should be assessed. Previous medical history of tuberculosis or epilepsy may suggest isoniazid or tiagabine induced seizures respectively. Prolongation of QRS on ECG points towards TCA, propoxyphene, venlafaxine, or diphenhydramine overdose. A sympathomimetic toxidrome prior to seizure activity suggest stimulant induced seizures or drug withdrawal. Serum levels of certain medications or toxins and sometimes drug screens may help clarify the aetiology $[2,9,23]$.

\section{Management of Drug induced seizures}

Majority of drug induced seizures clinically present as generalized tonic-clonic motor activity. It is often self-limited. However, prolongation of the convulsive muscle activity can lead to hypoxia, hypercarbia, pulmonary aspiration of gastric contents, lactic acidosis, hyperthermia and rhabdomyolysis. Initial treatment consists of airway management with adequate oxygenation and ventilation, stabilization of the blood pressure and heart rate and rapid testing of serum glucose concentration

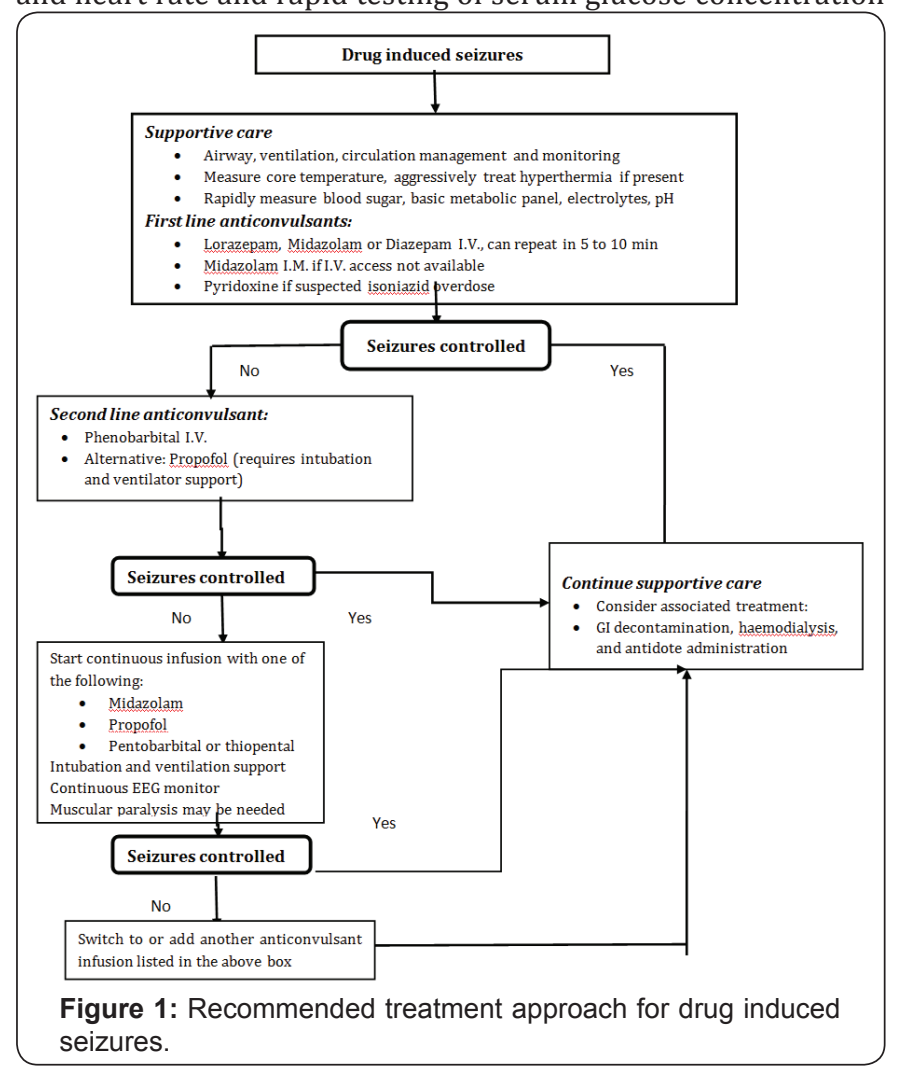

The recommended treatment approach for drug induced seizures is as depicted in the (Figure 1). The recommended first line anticonvulsant therapy in drug-induced seizures is benzodiazepines. Intravenous lorazepam is preferred initial benzodiazepine, although intravenous midazolam is also widely used. If intravenous access is not readily available, and then midazolam, being water soluble can be given intramuscularly [3]. Pyridoxine (vitamin B6) is an essential cofactor in GABA synthesis and effectively restores GABA synthesis. It is the drug of choice for seizures due to suspected isoniazid toxicity, and can also be used in poisoning by certain Gyromitra mushrooms [10].

If benzodiazepines are ineffective, barbiturates are recommended as the second line treatment. The drug of choice is phenobarbital. Studies have reported effectiveness of barbiturates in fluvoxamine-induced seizures resistant to benzodiazepines and phenytoin. Moreover, preclinical studies also suggest superiority of phenobarbital over phenytoin in prevention of theophylline-induced seizure and death $[3,9,23]$. Propofol is an alternative second line treatment as it may have an additive or synergistic effect when used with benzodiazepines or barbiturates. The efficacy to antagonize the NMDA receptor provides an advantage in case of seizures secondary to increased NMDA activity. However, relatively high cost, potential to cause hypertriglyceridemia, propofol infusion syndrome and neuroexcitatory events limit its use. Hence, it is usually reserved for patients with refractory status epilepticus [3].The doses of the first and second line anticonvulsants for the treatment of drug induced seizures is as given in the (Table 3).

Table 3: Anticonvulsants for drug induced seizures.

\begin{tabular}{|c|c|c|}
\hline Drug & Initial/ Loading dose & $\begin{array}{l}\text { Continuous } \\
\text { infusion }\end{array}$ \\
\hline Diazepam & $\begin{array}{c}5 \text { - } 10 \mathrm{mg} \text { IV (children: } 0.2 \text { to } \\
0.5 \mathrm{mg} / \mathrm{kg} \text { ) over } 2 \text { to } 5 \mathrm{~min}(\max \\
10 \mathrm{mg} / \text { day); may repeat every } \\
5-20 \text { min }\end{array}$ & $\begin{array}{l}\text { Note: contains } \\
\text { propylene glycol }\end{array}$ \\
\hline Lorazepam & $\begin{array}{l}2 \text { - } 4 \mathrm{mg} \text { IV (children: } 0.05 \text { to } \\
0.1 \mathrm{mg} / \mathrm{kg} \text {, max } 4 \mathrm{mg} / \text { day); may } \\
\text { repeat every } 5 \text { - } 10 \mathrm{~min}(\max \\
\text { rate: } 2 \mathrm{mg} / \mathrm{min})\end{array}$ & $\begin{array}{l}\text { Note: contains } \\
\text { propylene glycol }\end{array}$ \\
\hline Midazolam* & $\begin{array}{c}\text { I.V.: } 0.05-0.2 \mathrm{mg} / \mathrm{kg} \text { (children: } \\
0.1-0.3 \mathrm{mg} / \mathrm{kg}) \text { over } 20-30 \\
\text { sec }(\max 10 \mathrm{mg})\end{array}$ & $\begin{array}{l}0.05 \text { to } 2 \mathrm{mg} / \mathrm{kg} / \\
\text { hr titrated to } \mathrm{EEG}\end{array}$ \\
\hline Pentobarbital & $\begin{array}{c}\text { I.M.: } 0.1-0.2 \mathrm{mg} / \mathrm{kg}(\max 10 \\
\mathrm{mg})\end{array}$ & $\begin{array}{l}0.05 \text { to } 2 \mathrm{mg} / \mathrm{kg} / \\
\text { hr titrated to } \mathrm{EEG}\end{array}$ \\
\hline Phenobarbital & $\begin{array}{c}5-15 \mathrm{mg} / \mathrm{kg} \text { I.V. (children: } 3 \\
-15 \mathrm{mg} / \mathrm{kg} \text { ) no faster than } 1 \mathrm{mg} / \\
\mathrm{kg} / \mathrm{min}\end{array}$ & $\begin{array}{l}\text { Note: contains } \\
\text { propylene glycol }\end{array}$ \\
\hline Propofol \$ & $\begin{array}{l}15-20 \mathrm{mg} / \mathrm{kg} \text { I.V. no faster than } \\
1 \mathrm{mg} / \mathrm{kg} / \mathrm{min} . \text { An additional } 5- \\
10 \mathrm{mg} / \mathrm{kg} \text { dose may be given } 10 \\
\text { min after initial dose }\end{array}$ & $\begin{array}{l}1.5-10 \mathrm{mg} / \mathrm{kg} \\
\text { titrated to } \mathrm{EEG}\end{array}$ \\
\hline Thiopental & 1 -2 mg/kg I.V. & $\begin{array}{l}0.5-5 \mathrm{mg} / \mathrm{kg} / \mathrm{hr} \\
\text { titrated to EEG }\end{array}$ \\
\hline Thiopental & $\begin{array}{c}2-7 \mathrm{mg} / \mathrm{kg} \text { I.V. no faster than } 1 \\
\mathrm{mg} / \mathrm{kg} / \mathrm{min}\end{array}$ & $\begin{array}{l}0.5-5 \mathrm{mg} / \mathrm{kg} / \mathrm{hr} \\
\text { titrated to EEG }\end{array}$ \\
\hline
\end{tabular}

${ }^{*}$ Consider I.M. route when there is no I.V. access

$\$$ - Propofol is not recommended for infants and young children.

The role of phenytoin in drug induced seizures is questionable and not recommended. Pre-clinical studies and 
case reports have shown that phenytoin did not effectively terminate seizures produced by a variety of substances. Moreover, phenytoin may be harmful and exacerbate cardiac conduction abnormalities when used to treat seizures induced by lidocaine, theophylline, isoniazid, local anaesthetics and tricyclic antidepressants. Phenytoin was also ineffective in preventing recurrent alcohol withdrawal seizures in various studies [3]. Other anticonvulsant such as valproate is recommended for the prophylaxis of clozapine-induced seizures. However, it has been shown to increase the threshold for theophylline- induced seizures in preclinical study. Ketamine was useful in tetramine poisoning in which seizures were refractory to benzodiazepines and thiopental. Levetiracetam has been reported effective in patients with nerve agent and pilocarpine neurotoxicity. Other potentially effective therapies still in development include adenosine analogues and cannabinoid receptor agonists $[3,9]$.

\section{Conclusion}

Awareness about the potential of various drugs to cause seizures is important for all physicians, particularly those in emergency, neurology, or intensive care settings. Premarketing studies, case reports of adverse outcomes, post-marketing surveillance and physician alert notices do educate physicians to be aware of the potential hazards of a drug. Moreover, in a therapeutic set-up, identification of patients at increased risk of seizures is an important and potentially preventative step. Those with history or presence of progressive neurological disease, extremes of age, renal impairment (where relevant to the drug pharmacokinetics e.g., antibiotics) and co-administration of other drugs with neurotoxic or epileptogenic potential have an increased risk of seizure precipitation.

In an epileptic patient, it is prudent to optimise anticonvulsant drug therapy first. In some cases, anticipatory treatment may be possible. For example, using pyridoxine with isoniazid and avoiding theophylline or clozapine in patients with a history of epilepsy. It is easy to misattribute a changing mental status to other factors in acutely unwell, particularly older patients and in case of doubt, neurological clinical assessment and, if indicated, EEG should be considered. The patients should also be advised to inform their physicians of additions or changes in medications made either by other physicians or by patient using over the counter and/or complementary medicines. Additionally, periodic review of the necessity for, and the benefits and adverse effects of, the prescribed drugs should be made. Thus, rational prescribing and patient education are the best strategies to prevent drug-induced seizures $[1,2]$.

\section{References}

1. Franson KL, Hay DP, Neppe V, Dahdal WY, Mirza WU, et al. (1995) Drug-induced seizures in the elderly. Causative agents and optimal management. Drugs Aging 7(1): 38-48.

2. Murphy K, Delante N (2000) Drug-Induced Seizures. General Principles in Assessment, Management and Prevention. CNS Drugs 14 (2): 135-146
3. Chen HY, Albertson TE, Olson KR (2016) Treatment of drug-induced seizures. Br J Clin Pharmacol 81(3): 412-419.

4. Pesola GR, Avasarala J (2002) Bupropion seizure proportion among new-onset generalized seizures and drug related seizures presenting to an emergency department. J Emerg Med 22(3): 235-239

5. Lowenstein DH, Alldredge BK (1993) Status epilepticus at an urban public hospital in the 1980s. Neurology 43(3 pt 1): 483-488.

6. Finkelstein Y, Hutson JR, Freedman SB, Wax P, Brent J, et al. ( 2013) Drug-induced seizures in children and adolescents presenting for emergency care: current and emerging trends. Clin Toxicol (Phila). 51(8): 761-766.

7. Thundiyil JG, Kearney TE, Olson KR (2007) Evolving epidemiology of drug-induced seizures reported to a Poison Control Center System. J Med Toxicol 3(1): 15-19.

8. Reichert C, Reichert P, Monnet Tschudi F, Kupferschmidt H, Ceschi A, et al. (2014) Seizures after single-agent overdose with pharmaceutical drugs: Analysis of cases reported to a poison center. Clin Toxicol 52: 629-634.

9. Garcia PA, Alldredge BK (1994)) Drug-induced seizures. Neurol Clin 12(1): 85-99.

10. Puri MM, Kumar L, Vishwakarma PD, Behera D (2012) Seizures with single therapeutic dose of isoniazid. Indian J Tuberc 59(2): 100-102.

11. Hillbom M, Pieninkeroinen I, Leone M (2003) Seizures in alcoholdependent patients: epidemiology, pathophysiology and management. CNS Drugs 17(14): 1013-1030.

12. Perucca E, Gram L, Avanzini G, Dulac O (1998) antiepileptic drugs as a cause of worsening seizures. Epilepsia 39: 517.

13. Skowron DM, Stimmel GL (1992) Antidepressants and the risk of seizures. Pharmacotherapy. 12 (1): 18-22.

14. Montgomery SA (2005) Antidepressants and seizures: emphasis on newer agents and clinical implications. Int J Clin Pract 59(12): 14351440.

15. Davidson J (1989) Seizures and bupropion: a review. J Clin Psychiatry 50(7): 256-261.

16. Waring WS, Gray JA, Graham A (2008) Predictive factors for generalized seizures after deliberate citalopram overdose. Br J Clin Pharmacol 66(6): 861-865.

17. Hanson GR, Jensen M, Johnson M, White HS (1999) Distinct features of seizures induced by cocaine and amphetamine analogs. Eur J Pharmacol 377(2-3): 167-173.

18. Ruffman C, Bogliun G, Beghi E (2006) Epileptogenic drugs: A systematic review. Expert RevNeurother 6(4): 575589.

19. Talaie H, Panahandeh R, Fayaznouri M, Asadi Z, Abdollahi M (2009) Doseindependent occurrence of seizure with tramadol. J Med Toxicol 5(2): 636715.

20. Bahls FH, MA KK, Bird TD (1991) Theophyllineassociated seizures with therapeutic or low Serum concentrations: Risk factors for serious outcome in adults. Neurology 41(8): 13091312.

21. Khine H, Weiss D, Graber N, Hoffman RS, Avner JR, et al. (2009) A cluster of children with seizures caused by camphor poisoning. Pediatrics 123(5): 12691272.

22. Cox B, Durieux ME, Marcus MA (2003) Toxicity of local anaesthetics. Best Pract Res Clin Anaesthesiol 17(1): 111136.

23. Zaccara G, Muscas GC, Messori A (1999) Clinical features pathogenesis and management of drug-induced seizures. Drug Saf 5(2):109-151. 


\section{Your next submission with Juniper Publishers will reach you the below assets}

- Quality Editorial service

- Swift Peer Review

- Reprints availability

- E-prints Service

- Manuscript Podcast for convenient understanding

- Global attainment for your research

- Manuscript accessibility in different formats ( Pdf, E-pub, Full Text, Audio)

- Unceasing customer service

Track the below URL for one-step submission https://juniperpublishers.com/online-submission.php 